\title{
Educação para promoção da saúde infantil: relato de experiência em um assentamento de reforma agrária, Vale do Rio Doce (MG)
}

\author{
Education for child health promotion: \\ the experience with an agrarian reform settlement \\ in Vale do Rio Doce, Minas Gerais, Brazil
}

\author{
France M aria Gontijo Coelho 1 \\ Teresa Gontijo de Castro 2 \\ Flávia M ilagres Campos 3 \\ M aria Teresa Fialho de Sousa Campos 3 \\ Silvia Eloiza Priore 3 \\ Sylvia do Carmo Castro Franceschini 3
}

\footnotetext{
1 Departamento de Economia Rural, Universidade Federal de Viçosa (DER-UFV). Campus Universitário $s / n$, 36570-000, Viçosa M G. fmcoelho@ufv.br. 2 Departamento de Nutrição, Faculdade de Saúde Pública da Universidade de São Paulo (FSP-USP).

3 Departamento de Nutrição e Saúde, Universidade Federal de Viçosa (DNS-UFV).
}

Abstract This study reports a pedagogical experience of intervention for child health promotion in a land reform settlement in the Vale do Rio D oce, Brazil. Grouped and individualized pedagogical procedures were combined to create spaces for discussion of child health and nutrition issues. Diagnosis on health conditions of children under 5 was proposed; planned and the results were discussed in a community meeting. A second moment consisted of an individualized nutritional counseling offered to the children's mothers, emphasizing the health problems of high occurrence at this age. The topic of breastfeeding was debated with pregnant and lactating women and a course on Child Health Care was taught to monitor local childhood health. Results were satisfactory since there was a good participation of the community in the interventionist activities, from planning to implementation. The adopted strategy permitted to detect accepted and effective interventions, and the necessity to reformulate some of them with the community. Furthermore, from a theoretical and methodological point of view, the experience allowed to identify the limitations and potential of the actions by combining areas such as sociology and nutrition in multidisciplinary activities. The actions promoting health and education can contribute to overcome the feeling of social exclusion of a group.

Key words Health education and promotion, Childhood health, Social intervention
Resumo 0 trabalho relata uma experiência pe dagógica de intervenção para promoção da saúde infantil em um assentamento de reforma agrária no Vale do Rio D oce (M G). N o processo, procedimentos pedagógi cos grupais e individualizados foram combinados, criando espaços dialógicos de problematização da saúde e nutrição infantil. Foi proposto e planejado um levantamento diagnóstico das condi ções de saúde das crianças menores de 5 anos; a devolução e a discussão dos dados com a população se deram por meio de reunião coletiva. Foi efetuado atendimento nutricional individualizado às mães das crianças; tratado com as gestantes e nutrizes o tema do aleitamento materno e ministrado um curso de Vigilantes da Saúde das Crianças, com vistas ao monitoramento da saúde infantil no local. H ouve grande partici pação dos assentados nas intervenções, desde 0 planejamento atéa execução das atividades. A estratégia adotada permitiu detectar as intervenções aceitas, as mais efeti vas e as que deverão ser reformuladas com a comunidade. Do ponto de vista teórico e metodológico, a experiência permitiu observar os limites e potencialidades de ações que aproximam áreas de saber como sociologia e nutrição em atividades transdisciplinares.

Palavras-chave Promoção e educação em saúde, Saúde infantil, I ntervenção social 


\section{Introdução}

0 contexto no qual a experiência aqui relatada se dá é de um assentamento vinculado ao M ovimento dos Trabal hadores Rurais Sem-Terra (MST), no Vale do Rio Doce (MG). Como parte de um projeto de extensão universitária, implementado na forma de pesquisa interventiva, este trabalho vem sendo desenvolvido pela Universidade Federal de Viçosa (UFV) no Assentamento 1o de Junho, desde 1999, e envolve estudantes dos diversos cursos desta instituição. N este artigo, são feitas descrições e análises de uma das intervenções deste projeto no sentido da promoção da saúde infantil com as famílias do assentamento.

No Brasil, a organização do M ST tem como marco 0 ano de 1979. Ele surge como resposta às profundas transformações econômicas e formas de expropriação no campo, decorrentes da modernização agrícola dos anos do milagre econômico, situação que se agravou com a crise da industrial ização brasileira e com a crise energética mundial dos anos 70. Diante da situação de extrema espoliação, os trabalhadores rurais assumiram o desafio de tentar resistir no campo e buscar formas de luta pela terra, nas próprias regiões em que viviam ou em regiões para onde as lutas os conduzissem. Esta foi a base social e as condições estruturais que geraram o M ST. Inicialmente, no Sul do país, com a chegada das máquinas em substituição ao trabalho humano, na introdução de grandes áreas de plantação de soja, ou da construção de barragens, acelera-se a organização do M ST. N esta região, ocorre a primeira ocupação de terras por famílias trabalhadoras rurais sem-terra (Souza, 2000).

Em M inas Gerais, as atividades de reflexão do movimento dos trabal hadores rurais começaram dentro das Comunidades Eclesiais de Base e nos Sindicatos de Trabal hadores Rurais. $\mathrm{Na}$ região do Jequitinhonha e Mucuri, em 1986, alguns trabal hadores e sindicalistas entraram em contato com o M ST a partir da primeira ocupação do M ST no Estado, em 1988 no município de Novo Cruzeiro. Desta ocupação foram assentadas 25 famílias e o restante, na expressão dos assentados, veio descendo pelo mapa, da região do Jequitinhonha, passando pela região do M ucuri em direção ao Vale do Rio Doce.

Em 1o de junho de 1993, éocupada a fazenda Califórnia, no município de Tumiritinga. Nasce, então, o projeto de assentamento com 0 nome em alusão à data de sua ocupação. Entre tanto, apenas em 1997, as 82 famílias foram assentadas, em definitivo, no local (Coelho \& Botelho, 2000). A té a conquista definitiva das terras do 10 de Junho, as famílias que hoje o compõem seguiram uma trajetória de luta, opressão, fome e miséria, quadro que começou a se modificar depois de assentados.

Conforme dados levantados em 2000, pela coordenação da extensão universitária, base deste relato, a morte de crianças é uma questão recorrente na memória dos assentados desde a etapa anterior à luta, quando ainda eram meeiros, arrendatários ou assalariados rurais. $\mathrm{Na}$ quele levantamento, foi possível entrevistar 65 das 82 famílias oficialmente assentadas. Dessas, 33 disseram que não haviam perdido nenhuma criança, nem antes nem depois da luta, mas remetiam a casos vividos por seus vizinhos. 0 restante, 32 famílias, afirmou ter perdido crianças, óbitos que, ao serem somados, resultaram em 49 crianças, tendo 30 delas falecido antes da luta; 15 na época das ocupações e acampamentos; e apenas três já no Assentamento 1o de Junho. Q uestionados sobre o que havia causado as mortes, os entrevistados disseram, na época: passou da hora de nascer ou nem chegou a nascer - explicações mais freqüentes nas falas - desidratação, diarréia, infecção generalizada, asma e bronquite, atropelamento, anemia passada [sic], dentre outras expressões. A penas três famílias não sabiam dizer algo sobre o motivo da morte da criança. M erecem destaque, ainda, outras falas marcantes, como: não tinha comida; a criança estava aguada; morreu, na ocupação, no ventre da mãe, de tanto sofrer.

N um contexto como este, a proposta de real ização de um trabal ho com educação nutricional e saúde teve a finalidade de consolidar atitudes e práticas que conduzissem à melhoria da saúde da população, ef etivando-se mudanças ou alterações nos padrões de comportamento de grupo ou família, como bem orientaram Bissoli e Lanzillotti (1997).

$\mathrm{Na}$ medida em que o trabal ho desenvolvido neste assentamento baseava-se numa perspectiva metodológica participativa e dialógica, destacaram-se a importância de uma análise crítica do espaço social e político da intervenção e a necessidade do envolvimento ativo da população nos processos de promoção da saúde. Essa perspectiva permitiu o que Pancer e Nelson (1996) chamaram de empoderamento de grupos, pessoas e organizações, pois a participação ativa modifica o ambiente comunitá- 
rio, ao impulsionar a elaboração participativa de novas normas de comportamento, importantes para atingir melhores metas de saúde e bem-estar, social e politicamente definidas.

Considerando-se o que já se sabe sobre a história dos assentamentos de reforma agrária no Brasil e sobre o interesse científico em propor melhorias para o perfil de saúde infantil desses grupos sociais, desenvolveu-se este trabalho. Dessa forma, o objetivo deste artigo foi relatar as intervenções na saúde infantil em um assentamento de reforma agrária, feitas a partir de um diagnóstico prévio das condições de saúde infantil no Assentamento 1o de Junho. As intervenções aqui descritas basearam-se numa perspectiva teórico-epistemológica, pautada na possibilidade de transformações intersubjetivamente visadas e dialogicamente problematizadoras, que são estratégias de intervenção socialmente conseqüentes, como orientou Oliveira (1990). Como se verá adiante, a educação nutricional e em saúde fez-se nesse sentido, apesar de alguns impasses terem sido enfrentados na práxis cotidiana de sua efetivação.

\section{Metodologia}

0 trabalho aqui descrito foi realizado ao longo de quatro meses do ano de 2001, com três visitas a campo.

\section{Diagnóstico das condições de saúde infantil do assentamento}

Para iniciar o trabalho de promoção e educação em saúde infantil com os assentados, primeiramente foi sugerida a realização de um diagnóstico de saúde das crianças menores de 5 anos do local. Como proposta, este diagnóstico foi discutido com os dois grandes grupos sociais que compõem a população do assentamento: os "coletivos", que se organizam em uma cooperativa de produção (Coopernova), e os "individuais", que sobrevivem em lotes de produção familiar independentes. No estudo dessa configuração original, tanto de fatos como de entendimentos (que, por sua vez, é mútuo tanto entre os assentados como entre os agentes de intervenção), delinearam-se medidas prioritárias e necessárias para melhoria das condições de saúde do grupo infantil.

O Ministério da Saúde preconiza como atenção básica de saúde para crianças, o acompanhamento do crescimento e do desenvolvi- mento, o incentivo ao aleitamento materno e o controle das imunizações e da infestação parasitária, das diarréias e das infecções respiratórias agudas - IRAS (M inistério da Saúde, 2001). Além desses parâmetros, o levantamento inicial no assentamento incluiu a avaliação do estado nutricional de ferro das crianças e do consumo alimentar deste grupo por meio de questionário de freqüência alimentar.

Conforme orienta a literatura, no grupo infantil, a principal causa de anemia é a alimentação inadequada, uma vez que o desmame precoce e a introdução de alimentos inapropriados, associados à manuten ção de dietas basicamente lácteas, com insuficiente consumo de alimentos que são fontes de ferro e de al ta biodisponibilidade, agravam o quadro de anemia (Schmitz et al., 1998).

Para o diagnóstico inicial de saúde, foram obtidos dados de 69 crianças de 0 a 60 meses de idade ( $100 \%$ da população nesta faixa etária), com relação ao estado nutricional (antropometria e nível de hemoglobina), parasitose intestinal, tempo de aleitamento materno, práticas alimentares e calendário de vacinação. Verificou-se que 7,6\% delas apresentavam déficit nos índices peso/idade e estatura/idade [com referência no National Center for H ealth Statistics NCHS (1977)] e 47,5\%, baixa concentração de hemoglobina ( $\mathrm{Hb}<11 \mathrm{~g} / \mathrm{dL}, \mathrm{OMS}, 1972)$. Infestação parasitária foi detectada em $96 \%$ das crianças, e 34\% estavam com a vacinação atrasada. A mediana de tempo de aleitamento materno exclusivo foi de 30 dias, e observou-se inadequada freqüência de consumo de alimentos ricos em ferro, principalmente das carnes (metodologia detalhada em Castro et al., 2004).

Quanto aos aspectos éticos, o projeto de avaliação das condições de saúde e nutrição das crianças do assentamento foi aprovado pelo Comitê de Ética em Pesquisa da U niversidade Federal de Viçosa (M G). Para isso, durante 0 diagnóstico no assentamento, as crianças detectadas anêmicas e parasitadas receberam tratamento medicamentoso, prescrito pelo médico da Prefeitura M unicipal de Tumiritinga. As mães das crianças que estavam com a vacinação atrasada foram orientadas a procurar 0 centro de saúde do município para atualização, e as crianças com desnutrição grave (índice peso/idade- $\mathrm{P} / \mathrm{I}<$ percentil 3 da curva do N CHS1977) foram encaminhadas ao médico do município, com prioridade no atendimento. 


\section{0 processo}

\section{Panorama das condições de saúde infantil}

A apresentação dos resultados do diagnóstico de saúde das crianças menores de 5 anos foi feita em reuniões coletivas com os assentados, uma para os coletivos e outra para os individuais. Essas reuniões tiveram o intuito de esclarecer os problemas de saúde infantil detectados e apresentar propostas de intervenções mais emergenciais. Os recursos utilizados foram exposição dinamizada e gráficos "tipo pizza" com os resultados do percentual de desnutrição, anemia, infestação parasitária e vacinação atrasada. Foi apontado também que o baixo tempo de aleitamento materno, exclusivo até os 6 meses e a dieta pobre em ferro, detectados no diagnóstico, contribuíam para a ocorrência de anemia ferropriva e interferiam também no crescimento infantil.

N esse momento, tornaram-se visíveis aos agentes externos a tristeza e a preocupação dos assentados com o quadro apresentado. 0 sentimento de frustração ficou claro quando diziam coisas do tipo: ô gente, fizemos o que foi possível! mas a situação ainda está difícil. A apresentação dos dados, na forma agrupada, sensibilizou os pais e criou um sentimento coletivo ou grupal que os mobilizou para o envolvimento no processo de busca de soluções. Dentre as várias ações de intervenção acertadas na devolução dos dados, deu-se prioridade ao atendimento nutricional individualizado às mães das crianças, no espaço dos coletivos e individuais. Além disso, realizou-se reunião com gestantes e nutrizes, ocasião em que se falou da importância do aleitamento materno, e ministrou-se um curso para formação de Vigilantes da Saúde das Crianças no assentamento.

\section{Orientação individual sobre práticas de saúde e nutrição}

Logo após as reuniões coletivas, foram dadas orientações individualizadas às mães das crianças de 0-5 anos. Além do aconselhamento dietético e da exposição do estado nutricional de cada criança, foram dadas e reforçadas informações às mães sobre profilaxia de verminoses e anemia, sobre horários e forma de ministrar a medicação antiverminose e suplementação de ferro e sobre a vacinação da criança (se estava em dia ou não). 0 recurso instrucio- nal utilizado foi o cartão da criança, por meio do qual as mães podiam constatar em que ponto da curva de crescimento seu filho se encontrava. Foi também enfatizada a importância de se acompanhar o ganho de peso da criança, introduzindo, dessa forma, a importância do papel dos Vigilantes da Saúde das Crianças no assentamento.

\section{Reunião com gestantes e nutrizes}

A partir da observação do baixo tempo de al eitamento materno exclusivo observado (mediana de 30 dias), foi realizada reunião com as gestantes enutrizes, na qual se discutiu a importância da amamentação exclusiva até os seis me ses, e cuja técnica utilizada foi a exposição dinamizada. Além desta, foi adotada a técnica de demonstração, em que se utilizou modelo anatômico para mostrar como se fazem a ordenha do leite e a massagem para preparação das mamas antes de o bebênascer. Os recursos instrucionais usados foram o modelo anatômico e 0 ál bum seriado sobre amamentação, do M inistério da Saúde. 0 recurso instrucional auxiliar foi um folder sobre amamentação, o qual reforçou as informações repassadas durante a reunião.

\section{Capacitação e formação dos Vigilantes da Saúde das Crianças}

Originalmente, a criação de um grupo de Vigilantes da Saúde das Crianças foi proposta aos assentados, para que pessoas do assentamento se encarregassem de auxiliar a equipe de pesquisa no diagnóstico da saúde infantil. Tendo em vista que a presença da equipe da Universidade não seria constante no local, os Vigilantes ficaram encarregados de coletar as fezes das crianças nas casas e entregá-las ao laboratório de análises clínicas da prefeitura de Tumiritinga, para exame parasitológico. 0 grupo dos Vigilantes era formado por jovens assentados que haviam concluído o 2 o grau e estavam por conta do trabal ho na lavoura em apenas um turno do dia. 0 turno livre seria empregado nas atividades de "vigilância".

No entanto, dada a observação do comprometimento de crescimento e desenvolvimento das crianças a partir do diagnóstico de saúde inicial, foi proposto aos assentados que se ampliassem as funções dos Vigilantes. Segundo a proposta, estes deveriam se responsabilizar pelo monitoramento do crescimento e pelo desenvolvimento das crianças menores de 5 anos 
no Cartão da Criança, para encaminhar ao médico do município aquelas que estivessem tendo crescimento e desenvolvimento insatisfatórios (em risco nutricional).

A ampliação das atividades dos Vigilantes foi interessante, uma vez que 0 acesso dos assentados ao município mais próximo era difícil, devido à distância, e havia preocupação em detectar as crianças que estavam em risco nutricional, para as devidas providências.

Diante disso, uma forma de controle desse estado nutricional foi proposta por meio da capacitação e treinamento para uso da técnica de aferição de peso, cálculo da idade da criança e interpretação da curva de crescimento do Cartão da Criança, além de capacitação sobre ações básicas de saúde infantil (higiene, estímulo da mãe ao aleitamento materno exclusivo até os 6 meses e preparo do soro caseiro). $\mathrm{Na}$ forma de curso, essa capacitação foi realizada por duas acadêmicas de Nutrição (UFV-M G) e pela primeira autora do trabalho. Contudo, na realização do curso reuniram-se, além dos representantes dos assentad os coletivos e individuais, pessoas do município (agentes de Saúde da prefeitura de Tumiritinga e da pastoral da Criança) que nem mesmo moravam no assentamento. Destaca-se que essa atividade permitiu aproximação e quebra de estranhamento, 0 que é importante para os assentados, porque 0 reconhecimento social diante dos moradores do município é um aspecto indispensável ao pleno exercício da condição de cidadãos.

No início da capacitação, técnicas de dinâmica de grupo foram feitas, com o objetivo de ampliar o conhecimento e o entrosamento entre os participantes. Em seguida, foram reapresentados os resultados do diagnóstico de saúde infantil dos assentados, para que o grupo analisasse as informações em detalhes, reforçando a necessidade de providências para controlar os problemas detectados.

Nesse sentido, foi construída uma matriz Realidade-Processo-Desejo, como orientaram Pereira e Little (2000), que é uma técnica de Diagnóstico Rápido Participativo (DRP), muito utilizada em pesquisas/intervenções das ciências sociais. Tanto na colocação dos problemas quanto na elaboração das soluções e na definição dos encaminhamentos necessários, a intervenção dos agentes externos visou criar condições pedagogicamente motivadoras à participação.

Para repasse de informações e introdução ao tema central da capacitação, foi feita uma exposição dinamizada, na qual se enfocaram 0 papel do Vigilante da Saúde das Crianças e os instrumentos de controle (balança e cartão da criança). Como recurso didático foi elaborado um folder que continha informações sobre as ações do Vigilante da Saúde das Crianças, além de um cartão da criança, em modelo ampliado, da curva de crescimento da criança e uma balança com dinamômetro. 0 folder foi lido juntamente com os participantes, e os demais recursos instrumentais foram apresentados no momento oportuno.

A exposição dinamizada foi novamente aplicada para introdução do procedimento de cál culo da idade das crianças (necessária, juntamente com o dado de peso, para localização da criança na curva de crescimento do Cartão da Criança). Ao longo da exposição, foram realizados exercícios, monitorados pelas acadêmicas.

Com o objetivo de proporcionar aos Vigilantes a oportunidade de exercitar os conhecimentos apreendidos, fez-se uma demonstração técnica, com as respectivas repetições, para visualização dos procedimentos de pesagem e análise da curva de crescimento. Esta técnica pedagógica foi também adotada no preparo do soro caseiro.

Ao final do curso, foi realizada uma cerimônia de certificação dos Vigilantes da Saúde das Crianças, com presença de vários moradores do Assentamento e do município. Essa forma ritualística visou incentivar o grupo eformalizar a responsabilidade coletiva com a saúde das crianças.

\section{Resultados e discussão}

\section{Reuniões para devolução dos dados}

Apesar de nem todos os assentados terem comparecido às reuniões de devolução dos dados, foi expressivo o número dos que estiveram presentes e que efetivamente participaram dos debates. Durante essas reuniões, foi possível problematizar algumas formas de saber como, por exemplo, o uso e a qualidade da água vinda da Copasa. Para os assentados, a "água tratada", que passaram a receber desde 0 ano anterior, estaria livre de parasitas. Por este motivo, acreditavam que não necessitava ser filtrada, o que foi esclarecido com informações sobre a importância do uso do filtro. Tendo em vista o padrão econômico dos grupos, o preço dos filtros e velas foi considerado alto. Como os da- 
dos haviam evidenciado um problema de saúde ligado à água (parasitoses), um dos presentes sugeriu, após o debate, que fosse solicitado à prefeitura o fornecimento dos filtros. $\mathrm{N}$ ota-se que em reuniões como essas, nas quais são criadas oportunidades de debate dos problemas, não há apenas repasse de informações, mas resolução de impasses e respectivos encaminhamentos. Essas reuniões não têm, ou não devem ter, sentido terminal, mas serem efetivas no encaminhamento das soluções.

Outro exemplo, nesse sentido, deu-se na apresentação da importância do consumo de carnes para preven ção da anemia ferropriva na infância. Para os assentados, a pal avra carne referia-se apenas à carne bovina, ocasião em que foi necessário esclarecer-Ihes que carne representa um grupo de alimentos que inclui variados tipos do alimento (boi, frango, peixe, porco).

Além do repasse de informações, durante as reuniões foram demonstradas práticas caseiras de combate à verminose mais utilizadas pela comunidade (semente de abóbora, doce de jal apa, chá de hortelã e outros). Essas práticas foram valorizadas, mas, naquele momento, recomendou-se prudência no seu uso, destacando-se que só deveriam ocorrer após o tratamento da verminose com medicamentos apropriados, a serem orientados pelo médico do município. Tal proposta foi justificada e acatada, mediante a explicação de que as ervas poderiam expor ao perigo a criança com alta infestação de Ascaris lumbricoides, visto que este parasita pode atingir as vias aéreas superiores e levar a criança a óbito por asfixia.

Em linhas gerais, pode-se dizer que, em reuniões intersubjetivamente conduzidas, os resultados são sati sfatórios uma vez que os agentes externos, por meio do entendimento mútuo, se dispõem a ouvir e debater as versões sobre os mesmos dados, os significados dos termos utilizados e as medidas de melhorias possíveis. Dessa forma, a intenção de esclarecer a população sobre as condições que melhoram a saúde infantil ultrapassa a natureza puramente performativa da informação, dada por uma pretensa autoridade nata do saber científico. A proposta é transformar, no espaço social, a informação no que Bourdieu (1989) chamou de "propriedades atuantes", ou seja, em capacidades incorporadas como novos valores e condutas.

\section{Orientação individual às mães}

Durante a orientação individual às mães, foi possível observar que estas tinham conhecimento da importância de práticas adequadas de saúde e nutrição para o crescimento e desenvolvimento infantil. No entanto, as observações e os diálogos permitiram constatar que as condições de produção na agricultura e pecuária entre assentados são fatores determinantes das condições alimentares.

U m fato observado durante as orientações às mães foi a "surpresa" destas, quando ficavam sabendo que seu filho estava com "baixo peso 1 ", decorrente do déficit ponderal e estatural conjuntamente, o que "mascara" o baixo peso da criança.

As mães mostraram-se preocupadas com a situação de saúde de seus filhos e receptivas aos aconsel hamentos e encaminhamentos recebidos.

A pesar da orientação individualizada ter atingido o objetivo de esclarecimento, acredita-se que, se fossem utilizados al guns recursos didáticos visuais para abordar as verminoses $e$ sua profilaxia (cartazes, folder, etc), a aproximação da intervenção teria sido mais efetiva. Isso não foi possível porque os resultados dos exames parasitológicos só ficaram disponíveis na chegada do grupo de interven ção ao assentamento, o que impossibilitou o preparo prévio do material.

\section{Reunião com gestantes e nutrizes}

N esta reunião compareceram poucas gestantes e nutrizes, porque o horário coincidia com outras atividades comuns no assentamento (último capítulo de uma novela) e por ter sido em dia posterior à orientação individual izada às mães. Esperava-se um público de 20 gestantes e nutrizes, mas compareceram apenas seis.

Para os agentes externos, essa atividade foi aquém do esperado e desejado, mas permitiu uma reflexão mais interessante. As dificuldades na amamentação, que se julgava existir entre as mulheres, não se confirmaram. 0 problema descrito por elas não foi previsto, na complexidade estrutural que o caracteriza, no momento da capacitação. Elas disseram que, além da responsabilidade com o trabalho em casa, tinham a "roça" e um número de filhos muito grande para cuidar, o que dificultava o processo de amamentação exclusiva até os seis meses. Além disso, não acreditavam que o leite materno, 
oferecido de forma exclusiva até os seis meses, fosse capaz de "sustentar" a criança, como mostraram algumas falas expressas na reunião: $A$ criança chora muito só com o leite materno! Dando outra coisa, ela melhora. É porque o leite da mãe não sustenta. Tem menino que quanto mais mama, mais grita!... fiz um mingauzinho de maisena e ele dormiu.

Nessa atividade, as técnicas pedagógicas e os recursos instrucionais (até mesmo um antigo álbum seriado do M inistério da Saúde) não foram apropriados para auxiliar as mães no esclarecimento da necessidade de mudança de comportamento com relação à amamentação exclusiva até os seis meses de idade da criança. O padrão cultural existente e as condições econômicas da produção, nesse grupo de mães, eram bem diferentes da perspectiva informada na academia. Talvez outras atividades de intervenção fossem mais prudentes, como o debate e a problematização dos hábitos, observados por um monitoramento da rotina diária. Essas observações deveriam ser feitas por um período longo e por meio de visitas às casas, o que permitiria maior aproximação da orientação nutricional aos impasses e valores aos quais as nutrizes e gestantes do assentamento estavam submetidas.

\section{A capacitação dos Vigilantes da Saúde das Crianças}

No início deste trabalho, foi dada ênfase maior à questão da integração entre os participantes, para troca de idéias e experiências, 0 que permitiu a criação de identidades entre membros do grupo por meio da análise dos problemas em comum. Essa aproximação é benéfica, visto que a continuidade do trabal ho depende muito desse entrosamento. N esse sentido, a aplicação da técnica de construção da matriz Realidade-Processo-D esejo permitiu evidenciar a ocorrência de problemas de saúde comuns a moradores do assentamento e a outros moradores do município. Além disso, a reflexão propiciada permitiu encontrar soluções mais viáveis para os problemas de saúde infantil detectados pelos presentes.

Os exercícios de capacitação para uso do cartão da criança deram-se por meio de repetições para treinamento sobre o cálculo da idade das crianças. Foram bem aceitos pelos participantes, sendo, sobretudo, solicitada a prorrogação do tempo para essas atividades. Esperava-se que o cálculo da idade fosse a principal dificuldade dos educandos, mas a compreensão do grupo superou as expectativas. De maneira geral, as repetições mostraram-se eficientes e, nesse sentido, os objetivos foram alcançados. Os educandos mostraram-se interessados, tendo participação ativa. A capacitação foi considerada satisfatória pelo público, embora, ao final, sugerissem mais um tempo para o desenvolvimento das atividades.

\section{Conclusões a partir da experiência}

A estratégia de intervenção para promoção da saúde infantil neste assentamento permitiu que se detectassem as condutas pedagógicas mais efetivas e as menos efetivas durante sua aplicação. Ao interpretar a experiência, alguns aspectos teóricos e metodológicos da intervenção merecem ser reformulados, tanto conceitualmente na academia quanto com a comunidade, com vistas a aperfeiçoar princípios e práticas pedagógi cas comunitárias para atender às condições e às expectativas culturais locais.

Este trabalho permitiu uma análise crítica dos preconcepções que orientavam os agentes externos ou a universidade. 0 desconhecimento da complexidade das causas ou das dificuldades concretas que as mulheres do assentamento estavam enfrentando na manutenção da amamentação exclusiva até os seis meses coloca novos desafios a novas pesquisas. 0 que tem dificultado a manutenção da amamentação exclusiva até essa idade, além de uma valoração cultural mente definida e diferenciada da proposta acadêmica em sua importância, é o número de filhos por mulher (4 a 5 em média) e o papel que elas têm como mulheres trabal hadoras rurais, fundamental para manutenção produtiva da família.

N essas condições, além do trabalho no lar, elas precisam realizar o trabalho no campo (na roça), ficando sem tempo e sem lugar para colocar as crianças pequenas mais perto delas nas lavouras. A reestruturação do espaço do trabaIho é que poderia facilitar a amamentação por mais tempo. As mulheres que fazem parte da cooperativa têm quatro meses de licença-maternidade, em razão da base organizativa e institucional de que o grupo dispõe. Entretanto, as mulheres dos produtores familiares individuais, depois do parto, têm pouco tempo para voltar ao campo e não contam com nenhuma forma de previdência e remuneração durante 0 "resguardo" ou nos primeiros seis meses da criança. 
Nesse aspecto, deparou-se com um problema que vai além da questão pura dos modos de intervenção educativa para promoção da amamentação exclusiva até os seis meses. Com este trabalho, que é uma forma de pesquisa participativa, foi possível perceber que o funcionamento e a dinâmica social do trabalho e da produção no campo, além da estrutura interna de organização no assentamento em questão, colocam um desafio às políticas públicas de saúde na reforma agrária. A questão de gênero ou das mulheres trabalhadoras rurais deve ser problematizada tanto pelos governos quanto pelas associações comunitárias ou organizações cooperativas, pois o trabalho feminino não só produz alimentos, mas é responsável pela vida e pela saúde das crianças no campo.

U ma decorrência dessa intervenção foi o repasse para o conjunto dos assentados, homens e mulheres, de uma proposta de problematização das dificuldades que as mulheres enfrentam na amamentação, com o objetivo de elaborar alternativas de trabalho que criem condições favoráveis para que ela ocorra de forma exclusiva até os seis meses. $N$ ão se trata de apresentar soluções, mas de apresentar a si- tuação-problema e elaborar, em conjunto, estratégias mais eficazes de superação dos impasses. A conscientização da população é al go a ser construído com os grupos sociais, que são agentes de mudança internos, tanto quanto tentam ser os agentes externos. Não se trata de embutir consciência em mentes al heias, mas construir alternativas de forma orientada. N esse processo, novos valores podem ser criados a partir de novas práticas sociais que evidenciam aspectos ou resultados mais positivos.

A participação ea motivação dos indivíduos do assentamento, durante intervenções subseqüentes, podem indicar um futuro de sucesso nas atividades de saúde col etiva no 10 de Junho, tanto que, desde este trabalho até hoje (em 2004), o médico do município vai de quinze em quinze dias ao assentamento. N essa experiência constatou-se que a população conscientizou-se de que ações de promoção e educação em saúde podem contribuir para superação do sentimento de exclusão social, presente na memória de todos. A mobilização social para melhoria das condições de vida naquele espaço de esperança faz do assentamento um rico contexto de possibilidades, de aprendizagens e de saberes.

\section{Colaboradores}

FM G Coelho foi a responsável pela coordenação, planejamento, orientação metodológica e acompanhamento do trabalho de campo e trabalhou na redação e revisão do artigo. TG Castro e FM Campos fizeram a redação do manuscrito, o planejamento e a execução das atividades de campo. M TF Souza Campos foi responsável pela orientação técnico-pedagógica em nutrição e colaborou na revisão e sugestões ao artigo. SE Priori fez a orientação técnica em nutrição infantil, além da revisão do artigo; e SCC Franceshini trabalhou na revisão do artigo e no apoio técnico em nutrição.

\section{Agradecimentos}

As autoras agradecem a toda a comunidade do Assentamento 10 de Junho, pela receptividade, pela hospitalidade e pelo interesse na promoção da saúde infantil. 


\section{Referências bibliográficas}

Bissoli M C \& Lanzillotti HS 1997. Educação nutricional como forma de intervenção: avaliação de uma proposta para pré-escolares. Revista de $\mathrm{Nu}$ trição 10(2):107-113.

Bourdieu P 1989. 0 poder simbólico. Bertrand Brasil, Rio de Janeiro.

Brasil. M inistério da Saúde 2001. Atenção integrada às doenças prevalentes na infância. Disponível em <http://www.saude.gov.br/programas/scriança/criança/aidpi/aidpi1.htm>. A cessado em 15 de maio de 2001.

Castro TG et al. 2004. Saúde e nutrição de crianças de 0 a 60 meses de um assentamento de reforma agrária, Vale do Rio Doce-M G. Revista de N utrição 17(2). (no prelo).

Coelho FM G \& Botelho M IV 2000. Individual, coletivos e semi-coletivos: autonomia individual e referência coletiva, pp. 54-66. In Anais... X Congresso Internacional de Sociologia Rural. Rio de Janeiro: Sociedade Brasileira de Economia Rural (SOBER) e International Rural Sociology of Agriculture.

N CHS (N ational Center for Health Statistics) 1977. Growth curves for children, birth-18 years. United States. Department of $\mathrm{H}$ ealth, Education and Welfare (PHS) Publ. No. 78-1650 (series 11 no. 165). N ational Center for $\mathrm{H}$ ealth Statistics, Hyattsville, MD.
Oliveira RC 1990. O saber, a ética e a ação social. Revista Internacional de Filosofia XIII (2):7-22.

Organização M undial de Saúde (OM S) 1972. Anemias nutricionais. Genebra. (OMS - Série de Informes Técnicos, 405), Genebra.

Pancer SM \& N elson G 1996. Enfoques de la promoción de la salud basados en la comunidad: guia para la movilización comunitaria, pp. 166-182. In Organización Panamericana de la Salud. Promoción de la salud: una antología. Washington, DC, OPS.

Pereira JR \& Little PE 2000. DRPE - Diagnóstico Rural Participativo Emancipador: a base para o desenvolvimento sustentável dos assentamentos da reforma agrária. Viçosa, UFV. (M imeo)

Schmitz BAS et al. 1998. A prevalência de desnutrição e anemia em pré-escolares de Brasília - Brasil. Pediatria M oderna 34(4):155-164.

Souza MJ 2000. U ma educação do campo: o ensino fundamental em um assentamento na região do Rio D oce (M G). M onografia (pós-graduação lato sensu), D epartamento de Educação, U niversidade Federal de Viços).

Artigo apresentado em 23/06/2004

Aprovado em 24/02/2005

Versão final apresentada em 24/02/2005 